\title{
Simulating nitrogen long-term fate and transport processes at a regional scale with a surface and subsurface fully-coupled watershed model
}

\author{
$\underline{\text { Koji Mori }^{\text {a }}}$, Yasuhiro Tawara ${ }^{\text {a }}$, Aurelien Hazart ${ }^{\text {a }}$, Kazuhiro Tada ${ }^{\text {a }}$ and Hiroyuki Tosaka ${ }^{\text {b }}$ \\ ${ }^{a}$ Geosphere Environmental Technology, 2-1 Kanda-Awajicho, Chiyoda-ku, Tokyo 101-0063, JAPAN \\ Email: mori@getc.co.jp \\ ${ }^{b}$ Department of Systems Innovation, Graduate School of Eng., The University of Tokyo. 7-3-1 Hongo,
}

\begin{abstract}
Examining the watershed-inherent nitrogen loads and their reaction kinetics is important to understand past, present and future perspectives of water pollution. This study describes a recently developed watershed modeling tool for simulating the fate and transport of nitrogen coupled with biogeochemical reaction kinetics. The tool was integrated into the distributed physics-based, surface and subsurface fullycoupled fluids flow code GETFLOWS (Tosaka et al., 2000). It allows consideration of multiple chemical species (i.e. ammonium nitrogen, nitrate nitrogen, etc.) and their kinetics interactions caused by microbial activities. Point and non-point source nitrogen loads can be traced to estimate the exchange of contaminated water in surface and subsurface via the land-surface interaction.
\end{abstract}

The developed tool considers the following major processes which are often required for an integrated watershed modeling:

- Meteorological factor (rainfall, snowfall, air temperature, etc.)

- Evapotranspiraton

- Snowmelt

- Rainfall interception by vegetation covers

- Surface and subsurface fully-coupled water flow

- Air and water two phase, compressible fluid flow in geological porous media

- Reactive solute transport (advection, turbulence diffusion and hydrodynamic dispersion)

- Multiple biogeochemical reactions

- Point and non-point contaminant loads

- Sorption and desorption (generalized mass transfer processes between different phases)

The governing equations of these multiple processes were developed and then discretise by using an integral finite difference method for spatial and an implicit method for temporal variables. The developed tool was applied to an actual field site named the Lake Kasumigaura Basin in Japan. Long-term observations over the past several decades showed that the nitrogen concentration had steadily increase in the most inflowing rivers. This tendency is maintained by inflowing contaminated groundwater. To examine the possible sources and pathways of nitrogen contamination, we aimed to analyse reactive nitrogen discharged within the entire region of the watershed and to assess the impact of nitrogen load on Lake Kasumigaura through the inflowing river water and groundwater.

Simulated nitrogen concentrations in tributary rivers of Lake Kasumigaura and in the subsurface water matched closely the measured data (e.g., water discharge of rivers, groundwater level and nitrogen concentration). The computed nitrogen discharge from subsurface water to the rivers and the reservoir were examined, and it was clearly shown that nitrogen concentration in most of rivers and lake water are maintained by nitrogen discharge from subsurface water over a long period.

This paper presents a brief overview of the governing equations, the solution procedure and the practicable usage of the developed tool for sustainable water resource management. The results obtained of the Lake Kasumigaura Basin indicate that the developed tool is effective for simulation of the long-term nitrogen behaviour of surface and subsurface coupled with the watershed environments.

Keywords: $\quad$ Watershed modeling, Water quality, Nitrification, Denitrification, GETFLOWS 


\section{INTRODUCTION}

Understanding of interrelationships between sources, transport pathways and receptors of possible chemical pollutants in a catchment is helpful information in order to maintain a desirable quality of surface and subsurface water. From past experience, it is known that once enclosed water bodies are contaminated, improving the water quality is often difficult. Groundwater inflow is considered to be one of the key pathways of prolonged contamination. However, it is not straightforward to be able to answer the question of where the dominant pathway is. Groundwater contamination by pollutant loading from an entire region of land to water bodies depends on the place and time. These are part of pollutant dynamics in enclosed aquatic systems. It is helpful information in water resources management if we are able to estimate when and how pollutant inflows to the water bodies. Direct measurement of contaminant flux over the catchment scale is generally not feasible, and an integrated watershed modeling tool is considered to be a potentially effective tool for the task. Biogeochemical reactions in nitrogen cycling are important process to control nitrification and denitrification in catchment depending on oxidization reduction (redox) conditions. However, the recent advanced 3D modeling tools such as HydroGeoSphere (Therrien et al., 2010) and InHM (Heppner et al., 1999), integrating surface and subsurface hydrological processes over the catchment scale, unable to consider such reaction kinetics. We therefore developed a watershed modeling tool for simulating transport and fate of nitrogen, coupled with the biogeochemical reaction kinetics. The tool was integrated into the surface and subsurface fully-coupled flow computer code GETFLOWS (Tosaka et al., 2000). This allows consideration of an arbitrary number of chemical species (e.g. ammonium nitrogen, nitrate nitrogen, etc.) and their interactions through reaction kinetics caused by microbial activities. Moreover, we focused on spatial and temporal fluctuations of vertical water flux with and without pollutant through land surface to enable understanding of the pollutant linkages between geographical and water sources. In order to validate the model, the tool was applied to a watershed named the Lake Kasumigaura Basin, Japan. This paper presents a brief overview of the mathematical model, and demonstrates a representative application of the developed tool by simulating the long-term transport processes and fate of nitrogen at a regional scale watershed.

\section{SURFACE AND SUBSURFACE FULLY-COUPLED WATERSHED MODEL}

\subsection{Conceptual Model}

We consider fluid flow, solute transport and biogeochemical reaction coupled processes at the watershed scale with surface and subsurface interaction. This study treats a generalized fluid flow as an isothermal, compressible, multiphase and multicomponent fluid system. At the land surface, we considered the heterogeneous distribution of meteorological conditions, topography, land use/land cover (LULC), surface soil and water use, and their related hydrologic processes such as surface water flows, rainfall interception, evapotranspiration and snowmelt. Surface water including streams, hill slope and reservoir flows, are modelled as a depth-averaged, diffusive wave approximation. Air/water two phase flow in the subsurface is modeled together with interaction of the land surface processes. Different types of water use (e.g., intake/drainage of the water from/to the rivers, withdrawing groundwater resources) for daily life, industrial and agricultural purposes are considered, including for both surface and subsurface water.

With the surface and subsurface coupled fluid flow, reactive solute transport and biogeochemical interactions are modelled. Water dissolved species are transported by advection, diffusion and dispersion with biogeochemical reactions, adsorption and desorption (i.e., mass transfer through water and solid interface). Figure 1 shows such a schematic representation. Bioavailable forms of nitrogen $(\mathrm{N})$ and their transformation which occur depending on redox conditions are considered. Although $\mathrm{N}$ reaction kinetics is controlled by the availability of electron donor, acceptor and many environmental factors ( $\mathrm{pH}$, temperature, etc.), we selected simple

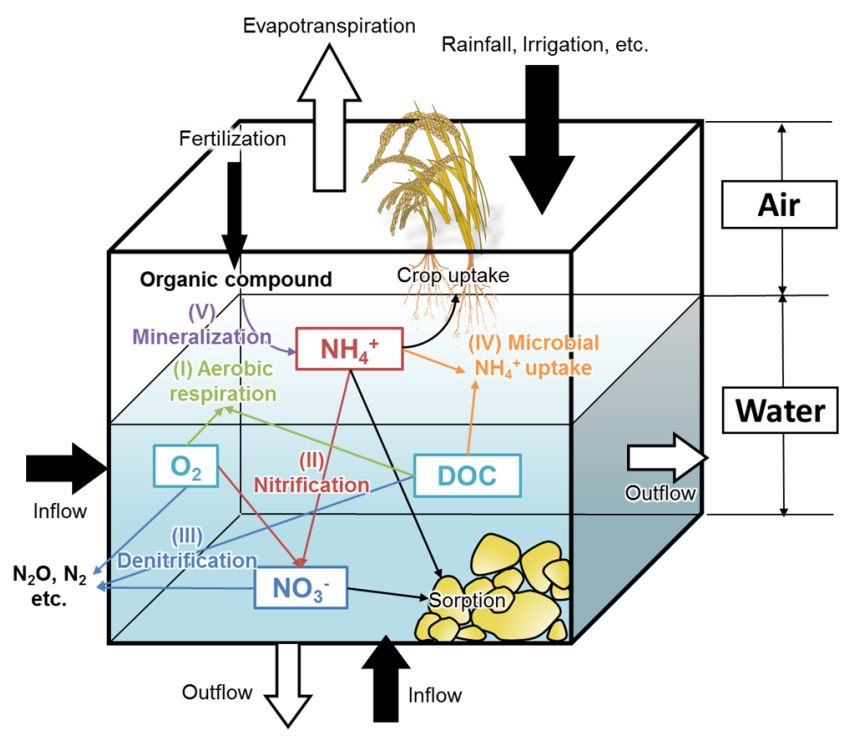

Figure 1. Schematic representation of fluid flow, solute transport and biogeochemical reaction coupled processes 
but dominant $\mathrm{N}$ transformation processes (Zarnetske et al., 2012). $\mathrm{N}$ transformation processes considered in this study are microbial $\mathrm{NH}_{4}^{+}$uptake, aerobic respiration, nitrification, denitrification and mineralization of the organic forms of $\mathrm{N}$. The multiple species in a system are dissolved oxygen $\left(\mathrm{O}_{2}\right)$, labile dissolved organic carbon (DOC), ammonium nitrogen $\left(\mathrm{NH}_{4}{ }^{+}\right)$and nitrate nitrogen $\left(\mathrm{NO}_{3}{ }^{-}\right)$. Organic carbon is represented as labile DOC and is assumed to exist in bioavailable form. The oxidation reaction from $\mathrm{NH}_{4}{ }^{+}$to nitrite nitrogen $\left(\mathrm{NO}_{2}^{-}\right)$is not considered here.

\subsection{Fluid Flow}

The governing equation for air/water two-phase fluid flow under an isothermal condition can be expressed by the following mass conservation equation.

$$
-\nabla \cdot\left(\rho_{p} u_{p}\right)-\rho_{p} q_{p}=\frac{\partial\left(\rho_{p} \emptyset S_{p}\right)}{\partial t} \quad(p=\text { water }, \text { air })
$$

where, $u_{p}$ is the fluid flow velocity $\left(\mathrm{m} \mathrm{s}^{-1}\right), \rho_{p}$ is the fluid density $\left(\mathrm{kg} \mathrm{m}^{-3}\right), q_{p}$ is the production and/or injection rate $\left(\mathrm{m}^{3} \mathrm{~m}^{-3} \mathrm{~s}^{-1}\right), \emptyset$ is effective porosity $(-)$, and $p$ is a subscripts representing the each fluid phases (i.e., $w=$ water, $a=$ air). The first term on the left-hand side of Eq (1) is the flow term, which is expressed by different average flow formula depending on surface and subsurface environment; Manning's law for the surface water flow and Darcy's law for the subsurface fluid flow. Air movement on the land surface is treated as a laminar flow together with large fluid mobility that is unable to affect water phase movement. Details on the mathematical treatment of surface and subsurface fluid exchange can be found in Tosaka et al. (2000).

\subsection{Solute Transport}

Solute transport in the above-mentioned fluid flow system is governed by an extended advection-dispersion equation that incorporates multiple sink/source terms, expressing adsorption/desorption, biogeochemical reactions, and so forth. We assumed that all of the chemical species are transported only in the water phase and the concentrations of solution are dilute (i.e., fluid properties are not affected by solute concentration). Then the governing equation for a species $i$ can be written by the following mass balance equation.

$$
-\nabla \cdot\left(u_{w} C_{w, i}\right)+\nabla \cdot\left(D_{w, i} \nabla C_{w, i}\right)-q_{w} C_{w, i}+m_{w \rightarrow s, i}-\sum_{\substack{i r=1 \\ i r \neq i}}^{N C} m_{w, i r \rightarrow i}+\sum_{\substack{j=1 \\ j \neq i}}^{N C} m_{w, i \rightarrow j}=\frac{\partial}{\partial t}\left(\phi S_{\mathrm{w}} C_{w, i}\right)
$$

where, $C_{w, i}$ is the solute concentration $\left(\mathrm{kg} \mathrm{m}^{-3}\right), D_{w, i}$ is the turbulence diffusion coefficient (for the surface) or the hydrodynamic dispersion coefficient (for the subsurface) $\left(\mathrm{m}^{2} \mathrm{~s}^{-1}\right), m_{w \rightarrow s, i}$ is the adsorption/desorption rate $\left(\mathrm{kg} \mathrm{m}^{-3} \mathrm{~s}^{-1}\right), m_{w, i r \rightarrow i}$ and $m_{w, i \rightarrow j}$ are the rate of biogeochemical reactions $\left(\mathrm{kg} \mathrm{m}^{-3} \mathrm{~s}^{-1}\right)$, and $N C$ is the total number of chemical species. Detail of reaction terms are described in the subsequent section. Hydrodynamic dispersion includes the effect of both molecular diffusion and mechanical dispersion, representing as a functional form $D_{w, i}=f\left(u_{w}, D_{m, i}, \alpha_{L}, \alpha_{T}, \phi, \ldots\right)$, where $D_{m, i}$ the molecular diffusion coefficient $\left(\mathrm{m}^{2} \mathrm{~s}^{-1}\right)$, $\alpha_{L}$ and $\alpha_{T}$ is the longitudinal and transverse dispersion length $(\mathrm{m})$, respectively. Different sorption models including well-known Langmuir and Freundlich type equations can be used depending on thermodynamic property of the interest solution system.

\subsection{Biogeochemical Reactions}

A multiple Monod kinetics equation (Monod, 1949) was employed to formulate the reactions terms of each species (DOC, $\mathrm{O}_{2}, \mathrm{NH}_{4}{ }^{+}, \mathrm{NO}_{3}{ }^{-}$) in Eq. (2). The generalized form of microbial reactions including aerobic respiration, nitrification, denitrification and microbial $\mathrm{NH}_{4}^{+}$uptake is described as follows.

$$
m_{w, i r \rightarrow i}=\mu_{i} X_{m} w_{m}\left(\frac{K_{I}}{K_{I}+C_{w, O_{2}}}\right)\left(\frac{C_{w, D}}{K_{D}+C_{w, D}}\right)\left(\frac{C_{w, A}}{K_{A}+C_{w, A}}\right)
$$

where, $\mu_{i}$ is the maximum rate constant $\left(\mathrm{h}^{-1}\right), X_{m}$ is the biomass of microbial functional group $(\mathrm{mg} / \mathrm{L}), w_{m}$ is the partition coefficient which can be derived from a bioenergenic relationship with free energy yield (dimensionless), $K_{I}$ is the non-competitive inhibition factor depending on $\mathrm{O}_{2}$ availability in denitrification reaction (dimensionless), $K_{D}$ and $K_{A}$ is the half-saturation constant $(\mathrm{mg} / \mathrm{L}$ ), the subscripts $\mathrm{D}$ and A represent the electron donor and electron acceptor, respectively.

This equation is applied to each reaction process (I) to (V) represented in Figure 1. For nitrification and denitrification, these reactions proceed with a non-competitive relationship via $\mathrm{O}_{2}$ consumption. $\mathrm{O}_{2}$ demand of nitrification is thermodynamically dominant. $\mathrm{O}_{2}$ concentration is considered to be an inhibiting factor of 
denitrification, taking a value between 0 and 1 . Aerobic respiration and nitrification are competitive reactions via $\mathrm{O}_{2}$ consumption. The competitive nature between the reactions is described using free energy thermodynamics. $\mathrm{NH}_{4}{ }^{+}$consumption by microbial uptake and nitrification can be considered in the same way. The mathematical expressions for each reaction term are detailed in Zarnetske et al., (2012). Mineralization of the organic forms of $\mathrm{N}$ can be expressed by the rate law of a first order reaction with the extended rate constant, taking account their different temperature conditions.

An advantage of a multiple Monod kinetics model is that there is no need to specify the temporal and/or spatial dependency of the rate constants explicitly that limits the microbial reactions. Depending on spatialtemporal distribution of the substrate concentration, the actual parameters can be implicitly evaluated with time and space. Therefore, it is possible to estimate when and where nitrification and/or denitrification occur predominantly by combining the surface and subsurface, coupled hydrology and biogeochemistry processes.

\subsection{Discretization and Solution Procedure}

Numerical solutions are obtained by employing an integral finite difference method for spatial and a fully implicit method for temporal variances to discretise the above governing equations. A parallel matrix solver can be applied to large-scale watershed problems. In a dilute solution system (where interactions do not occur between the flow field and concentration field) as mentioned above, each value can be determined in successively. More specifically, in the individual calculation steps, the flow field of the water phase is obtained by solving Eq. (1), and the advection dispersion equations in Eq. (2) are solved using the computed velocity field of water flow. These processes are implemented in the GETFLOWS (General-purpose Terrestrial Fluid Flow Simulator) simulator (Tosaka et al., 2000; Mori et al., 2015).

\section{APPLICATION TO THE LAKE KASUMIGAURA BASIN, JAPAN}

\subsection{Field Description and Model Development}

We applied the developed methods to the Lake Kasumigaura (KSM) basin, Japan (Figure 2). Lake KSM is the common name for the multiple bodies of water consisting of the Kitaura, Nishiura, and other lakes, which extend from the south-eastern part of Ibaraki prefecture to the northeastern part of Chiba prefecture. Lake $\mathrm{KSM}$ is the second largest lake in Japan by surface area.

Annual average precipitation in the catchment ranges approximately from 1248 to $1637 \mathrm{~mm} / \mathrm{y}$. Figure 2 shows land use distribution in 2006, which covers mostly farmland including livestock housing, paddy and dry field, and urban area that has expanded after 2000. The subsurface geology is comprised of surface soil, alluvial sediment group, Kanto loam, Joso clay strata, Shimofusa groups, Kazusa groups, tertiary and bedrocks. The upper parts of the diluvial terrace are broadly covered by Ibaraki clay strata originated from volcanic ash (equivalent to Joso clay strata) and Kanto loam strata.

We developed a 3D numerical model encompassing an area of 2,200 $\mathrm{km}^{2}$ as shown in Figure 3. Geographical data from national and local governments, such as meteorological factors, topography, LULC, water use,

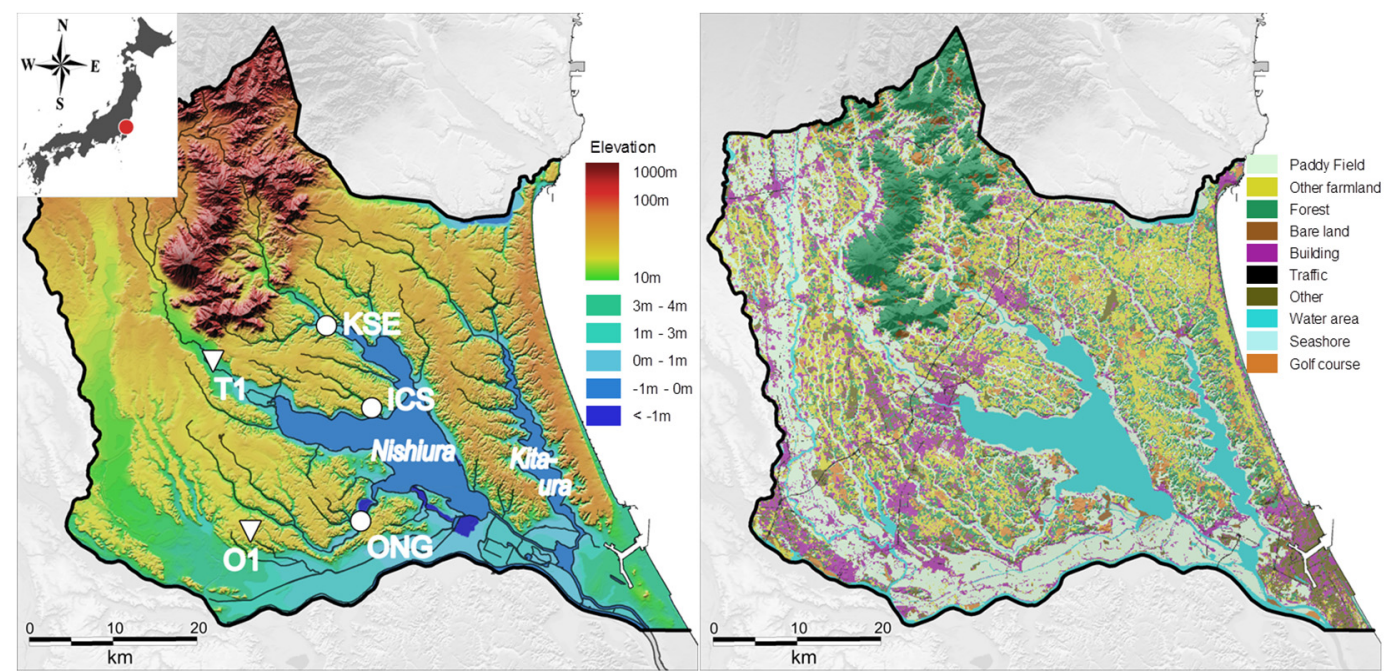

Figure 2. Study area for the Lake Kasumigaura: topography (left) and land use classification in 2006 (right). KSE, ICS and ONG denote monitoring stations of river discharge. T1 and O1 are monitoring wells of groundwater level. 
subsurface geology and $\mathrm{N}$ loads (point and non-point sources) were used for the model. Manning roughness coefficients were used, ranging from 0.02 to $0.4\left(\mathrm{~m}^{-1 / 3} \mathrm{~s}\right)$ for the corresponding LULC categories. Figure 3 shows the developed three-dimensional grid block system colored with respect to the geological facies. The hydraulic properties of each geology are summarized in Table 1, which were identified through history matching (calibration) using the measurement data of the river discharge (2006 to 2007) and the groundwater level (1960 to 2004).

$\mathrm{N}$ loads discharged from daily life, industrial and agricultural production were considered in the model. Drainage from different wastewater treatment plants is modeled as $\mathrm{N}$ load conditions of point sources, and the range is from $2 \times 10^{-5}$ to $7.65 \times 10^{-3}(\mathrm{~kg} /$ person $/ \mathrm{d})$. Moreover, the point source drainage emitted from industrial and farming facilities are assumed to be $488(\mathrm{~kg} / \mathrm{d})$ and $3.89 \times 10^{-3}-28.7 \times 10^{-3}(\mathrm{~kg} / \mathrm{head} / \mathrm{d})$ respectively. For paddy and dry fields, fertilization, mineralization of organic $\mathrm{N}$ and crop uptake are independently modelled as shown in Figure 1, and resultant $\mathrm{N}$ load by non-point source is implicitly loaded. Table 2 summarizes the biogeochemical kinetic reactions and the solute transport parameters. In order to discuss the applicability of the developed tool, the biomass was assumed to be constant, at $10 \mathrm{~kg} / \mathrm{m}^{3}$ for the whole simulation period.
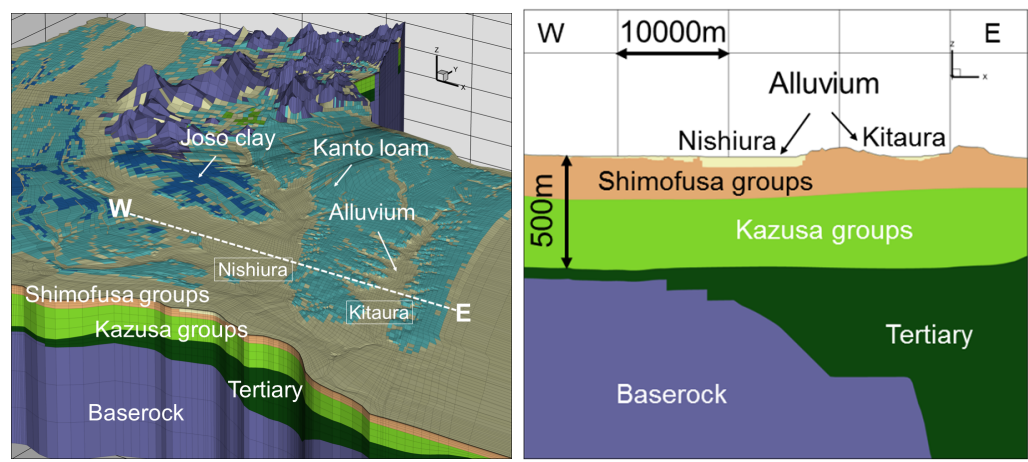

Figure 3. Bird eye (left) and depth section (right) views of the threedimensional hydrogeological model

\subsection{Simulation Procedures}

We aimed to analyse the dynamics of reactive $\mathrm{N}$ discharged from the whole watershed and to assess the environmental impact of $\mathrm{N}$ loading on the lake water. Observations during the past several decades show that the $\mathrm{N}$ concentration had been mostly increasing in the inflowing rivers. This tendency is assumed to be caused by the contaminated groundwater inflows. To examine the possible pathways of $\mathrm{N}$ contamination, we tried to reproduce the time sequence of $\mathrm{N}$ concentrations from 1960 to 2004 using the following subsequent steps.

Table 1. Hydraulic parameters

\begin{tabular}{lll}
\hline Geology & $\begin{array}{l}\text { Permeability } \\
(\mathrm{m} / \mathrm{s})\end{array}$ & $\begin{array}{l}\text { Effective } \\
\text { Porosity }(\%)\end{array}$ \\
\hline \hline Surface soil & $5.0 \times 10^{-4}$ & 40 \\
Alluvium & $1.0 \times 10^{-5}$ & 20 \\
Kanto loam & $1.0 \times 10^{-5}$ & 20 \\
Joso clay & $1.0 \times 10^{-7}$ & 20 \\
Simofusa group & $1.0 \times 10^{-5}$ & 20 \\
Kazusa group & $1.0 \times 10^{-6}$ & 20 \\
Tertiary & $1.0 \times 10^{-7}$ & 10 \\
Bedrock & $1.0 \times 10^{-9}$ & 5 \\
\hline
\end{tabular}

Firstly, we performed history matching using short-term observation data for 2 years (2006-2007). Daily fluctuations of meteorological conditions, nitrogen loads and groundwater pumping were constrained to the model. Simulated river water discharges were compared with the observed results. To obtain matching between the simulated and the observed data, the hydraulic parameters were slightly adjusted from their initial estimation. Next, the calibrated model was applied to long-term reproduction of the recorded groundwater levels (GWL) over almost 45 years $(1960$ - 2004). For more efficient computation, the time
Table 2. Biogeochemical kinetic reaction and transport parameters

\begin{tabular}{|c|c|c|c|c|}
\hline Parameters & & Unit & Values & Note \\
\hline \multicolumn{5}{|l|}{ Rate constant } \\
\hline Aerobic respiration & $\mu_{O 2}$ & $\left(\mathrm{~h}^{-1}\right)$ & $2 \times 10^{-3}$ & DOC, $\mathrm{O}_{2}{ }^{\mathrm{a})},(\mathrm{I})^{\mathrm{b})}$ \\
\hline Nitrification & $\mu_{N H 4}$ & $\left(\mathrm{~h}^{-1}\right)$ & $1 \times 10^{-3}$ & $\mathrm{NH}_{4}^{+}, \mathrm{O}_{2}{ }^{\text {a) }},(\mathrm{II})^{\mathrm{b})}$ \\
\hline Denitrification & $\mu_{N O 3}$ & $\left(h^{-1}\right)$ & $1 \times 10^{-3 \mathrm{c})}, 40^{\mathrm{d})}$ & $\mathrm{DOC}, \mathrm{NO}_{3}^{-\mathrm{a})},(\mathrm{III})^{\mathrm{b})}$ \\
\hline \multirow[t]{4}{*}{ Half-saturation constant } & $K_{O 2}$ & $\left(\mathrm{mg} \mathrm{L}^{-1}\right)$ & 5.28 & \\
\hline & $K_{N H 4}$ & $\left(\mathrm{mg} \mathrm{L}^{-1}\right)$ & 0.43 & \\
\hline & $K_{N O 3}$ & $\left(\mathrm{mg} \mathrm{L}^{-1}\right)$ & 1.64 & \\
\hline & $K_{D O C}$ & $\left(\mathrm{mg} \mathrm{L}^{-1}\right)$ & 8.68 & \\
\hline Inhibition factor & $K_{I}$ & $\left(\mathrm{mg} \mathrm{L}^{-1}\right)$ & 0.24 & \\
\hline \multirow[t]{2}{*}{ Partition coefficient } & $w_{N I T}$ & $\left(\mathrm{~kJ} \mathrm{~mol}^{-1}\right)$ & 0.27 & Nitrification \\
\hline & $w_{A R}$ & $\left(\mathrm{~kJ} \mathrm{~mol}^{-1}\right)$ & 0.73 & Aerobic respiration \\
\hline \multirow[t]{2}{*}{ Diffusion coefficient } & $D_{T}$ & $\left(\mathrm{~m}^{2} \mathrm{~s}^{-1}\right)$ & $1 \times 10^{-3}$ & surface water ${ }^{e}$ ) \\
\hline & $D_{m}$ & $\left(\mathrm{~m}^{2} \mathrm{~s}^{-1}\right)$ & $2 \times 10^{-9}$ & groundwater ${ }^{\text {f) }}$ \\
\hline \multirow[t]{2}{*}{ Dispersion length } & $\alpha_{L}$ & (m) & $10-100^{g)}$ & Longitudinal \\
\hline & $\alpha_{T}$ & (m) & $1-10^{\mathrm{g})}$ & Transverse \\
\hline Distribution coefficient & $K d_{N H}$ & $\left(\mathrm{~m}^{3} \mathrm{~kg}^{-1}\right)$ & 0.005 & $\mathrm{NH}_{4}^{+}$, Freundlich \\
\hline Sorption parameter & $a_{\mathrm{NO} 3}$ & $\left(\mathrm{~m}^{3} \mathrm{~kg}^{-1}\right)$ & 0.3967 & $\mathrm{NO}_{3}^{-}$, Langmuir \\
\hline Maximum sorption & $S_{N O 3}^{\max }$ & $\left(\mathrm{kg} \mathrm{kg}^{-1}\right)$ & 0.0018 & $\mathrm{NO}_{3}^{-}$, Langmuir \\
\hline
\end{tabular}

a) Chemical species in the each reaction, b) Reaction type depicted in Figure 1, c) Except paddy field, d) Paddy field, e) Turbulence diffusion, f) Molecular diffusion, g) consider scale (travel length) dependency 
resolution of data was averaged in monthly time intervals. Then, we investigated the model's reproducibility by comparing the monthly averaged $\mathrm{N}$ concentration with the measured values in the major inflowing rivers. Through these computations, we tried to identify the geological structure and hydraulic parameter that closely reproduce the multiple independent observed data without any inconsistencies. The historical changes in the $\mathrm{N}$ load used in the simulation were assumed to be based on relationship with the past population, land use, and so forth. Finally, we extracted the simulated $\mathrm{N}$ discharge to each of the primary rivers and the $\mathrm{N}$ budget of Lake KSM, and discussed on the possible pathways of water contamination.

\subsection{Results and Discussion}

Figure 4 compares the simulated and observed water discharge in the inflowing rivers at the different locations ONG and KSE denoted in Figure 2. Note that although a slight drop of less than $1 \mathrm{~m}^{3} / \mathrm{s}$ can be observed in the KSE at around April 2006, the simulation results closely match the measured data. Figure 5 shows a comparison of the long-term observed GWL and the simulation results at the stations $\mathrm{O} 1$ and T1. The difference between the observed and simulated GWL was less than $5 \mathrm{~m}$, clearly showing close agreement. For only the 3 years period from 1990 to 1993, the observed GWL at the station O1 was approximately $10 \mathrm{~m}$ lower than other periods. These are inferred to be abnormal values arising from the installation of the measurement devices or other related operations. Figure 6 compares the simulated and measured concentrations of total N (TN) in the different locations KSE and ICS. Both simulated results show that the measurements of the long-term changes in TN concentration were reasonably reproduced. These simulation results of water discharge and TN concentration in the rivers, that favourably matched the observed data, were also obtained at another 10 rivers but are not shown here. These results indicate that the developed model reproduced successfully the measured data over both short- and long-period.

From the long-term simulation results, we extracted the TN discharge at 12 inflowing rivers and the $\mathrm{N}$ budget of Lake KSM. Figure 7 (a) shows the results of the 12 inflowing rivers, which are the direct $\mathrm{N}$ load to the Lake KSM. These estimated trends differ depending on the regional characteristics of both $\mathrm{N}$ load and biogeochemical reaction processes in each river basin. Results show that the TN discharge through all of the inflowing rivers increased steadily over the entire period. This indicates that the $\mathrm{N}$ concentration is continuously affected by the supply of contaminated groundwater through the river bed. Figure 7 (b) shows the discharges of $\mathrm{N}$ into the Lake KSM, from surface water and groundwater. The amount of inflowing $\mathrm{N}$ of both pathways shows a trend of gradual increase over a long period of time. Although the simulation results of the surface water and groundwater inflow in the same period were $34 \mathrm{~m}^{3} / \mathrm{s}$ and $1 \mathrm{~m}^{3} / \mathrm{s}$, respectively, no trends were observed in longterm change over this period. It is therefore difficult to consider the $\mathrm{N}$ concentration increase that accompanies increase or decrease in the

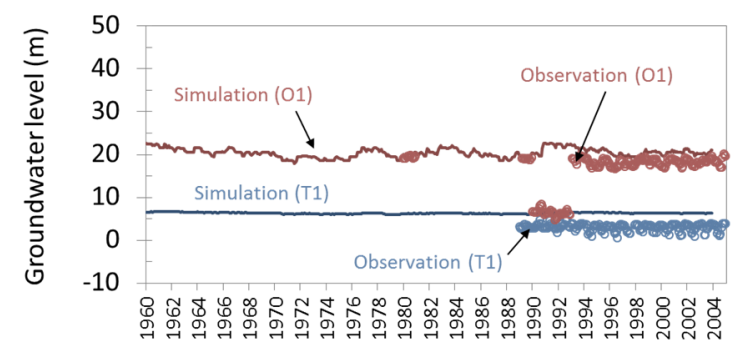

Figure 5. Comparison of simulated and observed GWL: O1 and T1 denote different locations (Figure 2).

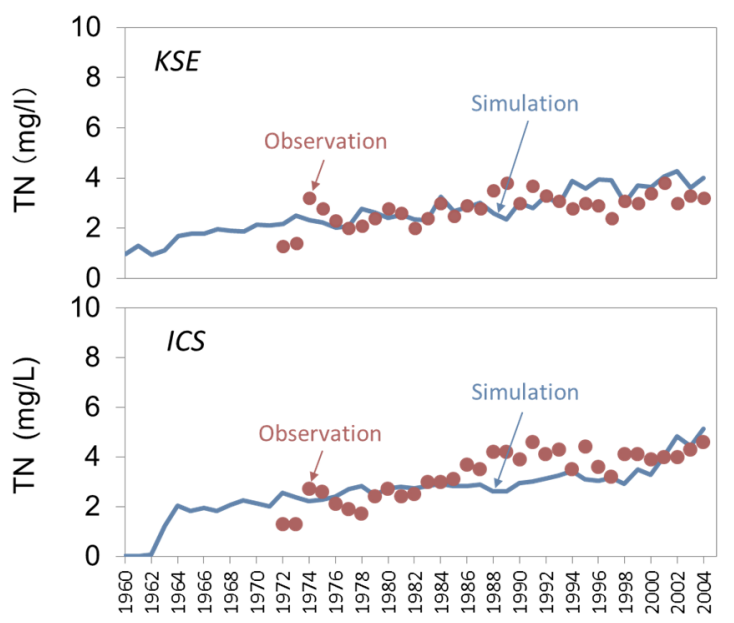

Figure 6. Comparison of simulated and observed TN: KSE and ICS denote different locations (Figure 2). 


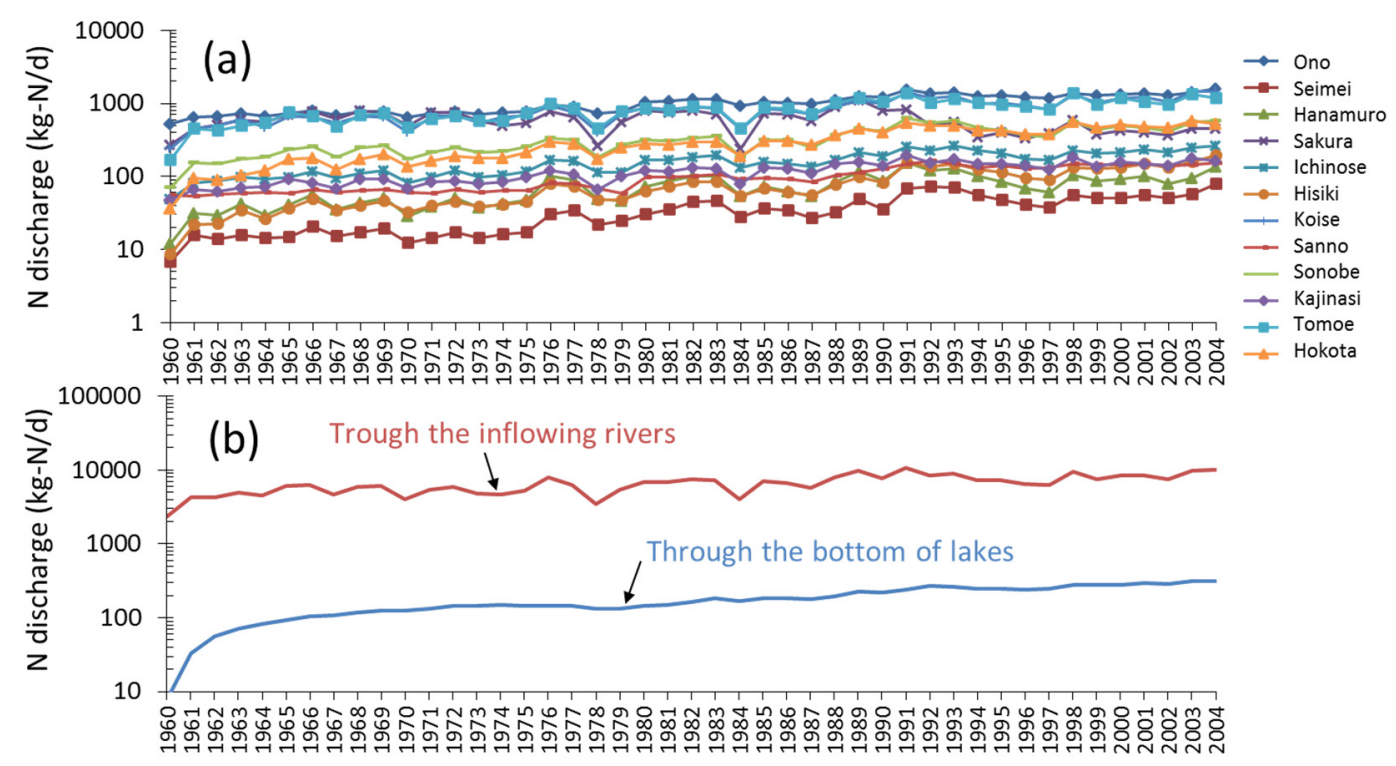

Figure 7. Estimated $\mathrm{N}$ discharges of the 12 inflowing rivers (upper) and the Lake Kasumigaura (lower). Red and blue lines in the lower graph show each contaminant pathway of $\mathrm{N}$ load via river water and groundwater.

amount of water inflow. As an estimated result, the $\mathrm{N}$ concentration in the river water shows an increasing trend due to the effect of $\mathrm{N}$ discharge of the contaminated groundwater. This trend can be considered to be the same as seen in Lake KSM. From these results, our simulation model showed that the N load on the Lake $\mathrm{KSM}$ is clearly characterized by long-term inflows of contaminated groundwater in addition to river water.

\section{CONCLUSION}

We developed a watershed modelling tool for simulating the transport and fate of nitrogen coupled with biogeochemical reaction kinetics. The tool was integrated into the computer code GETFLOWS. It allows consideration of a number of chemical species and their reaction kinetics and interactions caused by microbial activities under surface and subsurface coupled hydrological fields. We demonstrated the model application to field data of the Lake Kasumigaura Basin. Simulation results of nitrogen concentrations in tributary rivers of Lake Kasumigaura and in the subsurface waters matched reasonably well with measured data. Using the validated numerical model, the estimated nitrogen discharge from subsurface water to the rivers and the lake water clearly showed that nitrogen concentration levels are mostly dominated by continuous groundwater discharge and this has occurred for a long period. The developed tool is particularly effective to simulate long-term nitrogen behavior in case where surface and subsurface processes over the watershed scale have to be considered simultaneously.

\section{REFERENCES}

Monod, J., (1949). The Growth of Bacterial Cultures. Annual Review of Microbiology 3, 371-394

Heppner, C. S., Ran, Q., VanderKwaak, J. E., and Loague, K. (2006). Adding sediment transport to the integrated hydrology model (InHM): Development and testing. Advances in Water Resources, 29(6), 930943.

Mori, K., Tada, K., Tawara, Y., Ohno, K., Asami, M., Kosaka, K., and Tosaka, H. (2015). Integrated watershed modeling for simulation of spatiotemporal redistribution of post-fallout radionuclides: Application in radiocesium fate and transport processes derived from the Fukushima accidents. Environmental Modelling \& Software, 72, 126-146.

Therrien, R., McLaren, R. G., Sudicky, E. A., and Panday, S. M. (2010). HydroGeoSphere: A threedimensional numerical model describing fully-integrated subsurface and surface flow and solute transport. Groundwater Simulations Group, University of Waterloo, Waterloo, ON.

Tosaka H., Itho K. and Furuno T., (2000). Fully coupled formulation of surface flow with 2-phase subsurface flow for hydrological simulation, Hydrological Process 14, 449-464

Zarnetske, J. P., Haggerty, R., Wondzell, S. M., Bokil, V. A., \& González-Pinzón, R. (2012). Coupled transport and reaction kinetics control the nitrate source-sink function of hyporheic zones, Water Resources Research 48 